\title{
Photoprotection for Skin of Color
}

\author{
Jerry Tsai ${ }^{1}$ · $\cdot$ Anna L. Chien ${ }^{1}[$
}

Accepted: 14 December 2021 / Published online: 19 January 2022

(C) The Author(s), under exclusive licence to Springer Nature Switzerland AG 2022

\begin{abstract}
Photoprotection behaviors can mitigate skin damage caused by ultraviolet radiation, and common methods include seeking shade, avoiding sun exposure during peak daylight hours, wearing sun-protective clothing, applying sunscreen, and using sunglasses. While the role of sun protection in preventing sunburns, photoaging, and skin cancer is well established in fair-skinned populations, individuals with skin of color (SOC) are presumed to suffer fewer negative effects from solar radiation. Thus, the importance of photoprotection in this population is understudied and may be underestimated. In SOC populations, sun exposure is known to cause pigmentary disorders, photoaging, and basal cell carcinoma (BCC), highlighting the potential benefits of photoprotection. Although SOC populations tend to practice photoprotection by seeking shade and wearing sun-protective clothing, survey and interview-based studies have consistently found relatively low use of sunscreen among these populations. Common motivators for photoprotection in individuals with SOC include preventing sunburn and pigmentation, with the prevention of skin cancer being a less important reason. As a skin cancer risk behavior, indoor tanning is relatively rare in SOC populations, but its use may increase with acculturation to US norms. While more studies are necessary to clarify whether photoprotection behaviors may decrease skin cancer-related mortality in SOC populations, regular dermatologic care and counseling on photoprotection remain essential in patients with SOC for overall skin health.
\end{abstract}

\section{Key Points}

Photoprotection is important to prevent the development and exacerbation of pigmentary disorders, photoaging, and basal cell carcinoma in patients with skin of color (SOC).

Common motivators for photoprotection in patients with SOC include preventing sunburn and pigmentation.

Sunscreens based on inorganic filters (e.g., titanium dioxide, zinc oxide) are often impractical for SOC due to their unfavorable cosmetic appearance, leaving patients to rely on sunscreens with organic filters or other forms of photoprotection (e.g., seeking shade, wearing sunprotective clothing, avoiding sun exposure).

Regular dermatologic care and counseling on the options and health benefits of photoprotection remain essential in patients with SOC.

Anna L. Chien

achien3@jhmi.edu

1 Department of Dermatology, Johns Hopkins University School of Medicine, 601 N Caroline Street, Suite 8060C, Baltimore, MD 21287, USA

\section{Introduction}

Photoprotection behaviors can prevent skin damage by ultraviolet (UV) radiation. The American Academy of Dermatology recommends practicing multiple forms of photoprotection to prevent photodamage and skin cancer [1], and common methods include seeking shade, avoiding sun exposure during peak daylight hours, wearing sun-protective clothing, applying sunscreen, and using sunglasses. While the role of photoprotection in preventing sunburns and the long-term consequences of sun exposure (e.g., photoaging, photocarcinogenesis) is well established in fair-skinned populations, individuals with dark skin are less likely to experience these outcomes, which may affect the perceived importance of practicing photoprotection. To discuss the potential benefits of photoprotection for these populations, it is necessary to first review biological and social factors relevant to the concept of skin of color (SOC).

Various methods have been developed to classify skin pigmentation, which arises from the interaction of external light with chromophores within the skin, such as melanin, hemoglobin, bilirubin, and $\beta$-carotene [2, 3]. Among these molecules, melanin contributes significantly to differences in skin pigmentation between light- and dark-skinned individuals, as well as darkening of the skin (i.e., tanning) after UV 
exposure [4-6]. The Fitzpatrick skin type (FST) categorizes skin based on self-reported likelihood to experience sunburn and tanning with sun exposure and ranges from type I (always burns, never tans) to type VI (never burns, always tans) [7]. FST is correlated with skin pigmentation, which becomes increasingly darker from FST I (pale white) to FST VI (dark brown or black) [8]. While not a perfect system, in dermatological practice clinicians often determine FST based on visual observation of the patients' skin color [9]. Quantitative methods such as colorimetry and spectrophotometry [3, 10-14] have been studied but are rarely used in clinical practice.

The terms 'SOC' and 'ethnic skin' refer to individuals with darker skin complexion compared with White individuals and typically include those with FST IV, V, and VI [15]. Examples of racial and ethnic groups that have been categorized under SOC in the US include Hispanics, Asians, African Americans, and Native Americans, among others $[15,16]$. While individuals of the same race and ethnicity may share similar phenotypic characteristics, these selfidentifications may also reflect shared cultures and values, consistent with the socially defined nature of racial and ethnic groups $[17,18]$. The use of race and ethnicity to define SOC is complicated by the significant heterogeneity in skin phototype and pigmentation within individual groups. For instance, prior studies have found that clinician-graded FST may range from $\mathrm{I}$ to $\mathrm{V}$ among Hispanic/Latino individuals $[9,13]$, from II to $\mathrm{V}$ among Asian/Pacific Islander individuals [13], and from IV to VI among Black individuals [9, 13]. Self-reported FST also varies significantly within racial and ethnic groups $[9,19]$ and may be inadequate for predicting the minimal erythema dose in Asian and Hispanic/Latino populations [20-22]. For these reasons, caution should be exercised in interpreting race/ethnicity and FST as surrogates for skin color. However, the use of self-identified race and ethnicity in epidemiologic studies may aid the study of health behaviors from a psychosocial perspective, given the possibility of shared attitudes and practices within racial and ethnic communities. Given this framework, the current article reviews photoexacerbated conditions such as pigmentation, photoaging, and photocarcinogenesis as well as photoprotection in SOC. We discuss motivating factors and barriers to photoprotection commonly reported by individuals with SOC, followed by recommendations on photoprotection for these patient populations.

\section{Pigmentation and Pigmentary Disorders}

Pigmentation in SOC arises from elevated levels of melanin, which is synthesized by melanocytes in the basal layer of the epidermis and stored in melanosomes for trafficking to surrounding keratinocytes. Compared with lighter skin, darker skin tends to have higher melanin content and number of melanosomes, but no difference in the number of melanocytes is seen $[5,15,23-26]$. The size and distribution of melanosomes follow a gradient across skin types, with smaller and grouped melanosomes in lighter skin and larger and non-grouped melanosomes in darker skin [15, 27, 28].

By absorbing, scattering, and reflecting incident light, epidermal melanin attenuates the transmittance of potentially damaging radiation to deeper skin structures; this includes UVA radiation (320-400 nm) that contributes most to photoaging and UVB radiation (280-320 nm) that contributes most to sunburn and skin cancer development [6]. In a study that measured UV transmission through epidermal sheets isolated from human cadavers, UVA transmission through black epidermis was one-third that of white epidermis (17.5\% vs. $55.5 \%$ ), while UVB transmission through black epidermis was one-quarter that of white epidermis (7.4\% vs. $29.4 \%$ ) [29]. In terms of sun protection factor (SPF), based on protection against UVB radiation, black epidermis was estimated to have an SPF of 13.4, nearly four times greater than that of white epidermis [29]. Consistent with these findings, individuals with darker skin pigmentation are less likely to experience sunburns and more likely to experience tanning after exposure to UV radiation [30-32]. Differences in tanning response among skin types may arise from the degree of melanin redistribution from basal to upper layers of the epidermis following UV exposure [26], as well as differences in levels of protease-activated receptor 2 , which mediates the uptake of melanosomes by keratinocytes in a UV-inducible manner [33, 34]. In addition to UV radiation, melanin can also play a role in visible light $(400-700 \mathrm{~nm})$ exposure, which has received increased study in recent years for its ability to independently induce skin erythema and hyperpigmentation [35, 36].

Despite increased photoprotection provided by darker skin, individuals with SOC are more susceptible to developing certain pigmentary disorders. While a comprehensive discussion of pigmentary disorders in SOC is beyond the scope of this review, post-inflammatory hyperpigmentation $(\mathrm{PIH})$ and melasma deserve mention as two of the most common conditions in this category that disproportionately affect patients with darker skin. PIH is characterized by the formation of hyperpigmented macules and patches following skin inflammation (e.g., acne, eczema) or injury (e.g., trauma, sunburn) [37]. Due to the risk of causing PIH, dermatologic procedures associated with significant skin damage, such as deep chemical peels and ablative lasers, are relatively contraindicated in SOC [37]. Melasma presents with hyperpigmented macules and patches, most commonly on the face with a symmetric distribution, and is also frequently seen in African Americans, Hispanics, and Asians [38, 39]. These cosmetically disfiguring pigmentary disorders may significantly impact quality of life $[37,38,40,41]$ and are 
among the top reasons for dermatology visits among patients with SOC $[42,43]$. The practice of photoprotection methods such as sun avoidance and sunscreen use are essential to prevent the development and worsening of PIH and melasma [37, 38]. Besides UV radiation, visible light has also been found to exacerbate PIH and melasma, which may be mitigated by using sunscreens containing non-micronized inorganic filters (e.g., titanium dioxide, zinc oxide) or tinted sunscreens that combine iron oxide or titanium dioxide pigments with inorganic UV filters [36, 44]. The practice of sun protection in individuals with SOC may also modulate two other long-term effects of UV and visible light exposure, namely photoaging and photocarcinogenesis.

\section{Photoaging}

The skin undergoes premature aging with sun exposure, also known as extrinsic aging or photoaging. While both UVA and UVB radiation contribute to photoaging, UVA radiation is up to 20 -fold more abundant than UVB radiation in sunlight and plays a greater role in photoaging due to its ability to reach the deep dermis (whereas UVB only reaches the upper dermis) [45-48]. In addition to promoting the release of reactive oxygen species (ROS) from the mitochondria and causing DNA damage, UV radiation also stimulates activator protein 1 (AP-1), which leads to the upregulation of matrix metalloproteinases (e.g., MMP1, MMP3, MMP9) and subsequent breakdown of dermal collagen and elastin [49]. UV-induced activation of AP-1 also inhibits transforming growth factor (TGF)- $\beta$ signaling, which is responsible for dermal collagen regeneration [49]. Visible light, which has longer wavelength and penetrates deeper in the skin, has also been shown to induce the production of ROS and MMPs, albeit to a lesser extent than UV radiation [50]. The accumulation of photodamaged collagen and elastic fibers, or solar elastosis, is one of the histological hallmarks of photoaging and contributes to the major clinical features of photoaging [51].

Clinical manifestations of photoaging are similar to, but do not completely overlap with, those of chronologic or intrinsic aging. Whereas chronologic aging primarily presents with fine wrinkles, soft tissue volume loss, and increased skin laxity, photoaging is more likely to present with coarse wrinkles, telangiectasias, solar lentigines, mottled hyperpigmentation, and skin dullness [46, 47]. Due to protection by epidermal melanin, individuals with SOC develop wrinkles from sun exposure later in life than those with lighter skin $[23,52-55]$. Nevertheless, histological evidence of solar elastosis in sun-exposed skin has been observed in Hispanics [56], Asians [39], and African Americans $[57,58]$. Features of photoaging more likely to develop in SOC have also been found. In addition to wrinkling, photoaging commonly manifests in Asians as pigmented spots, solar lentigines, and pigmented seborrheic keratoses [39, 52, 53, 59]. In African Americans, photoaging is associated with hyperpigmentation, dyschromia, increased skin laxity, and dermatosis papulosa nigra [55]. Hispanics often show significant heterogeneity in skin types, and predominant signs of photoaging may exist on a gradient between those commonly seen in light- and dark-skinned individuals $[47,55]$. Differences in prominent features of photoaging have led to the development of photonumeric scales for grading skin photoaging in specific racial and ethnic groups, including Caucasians [60, 61], Asians [59], and African Americans [62].

The positive relationship between sun exposure and increased severity of photoaging is well established in fairskinned individuals, and similar associations have been found in Asian [59] and African American participants [62]. Due to the increased risk of PIH with certain dermatological procedures (e.g., dermabrasion, deep chemical peels, ablative lasers), caution is necessary to select modalities less likely to cause PIH (e.g., topical retinoids, fillers, superficial chemical peels, and non-ablative and/or fractionated lasers) when treating photoaged skin in patients with SOC [55]. Nevertheless, photoprotection remains the most important method for preventing photoaging and its associated psychosocial consequences in patients with SOC [16, 63, 64].

\section{Photocarcinogenesis}

UV radiation, especially UVB radiation, is associated with the development of melanoma and non-melanoma skin cancer (NMSC; e.g., basal cell carcinoma [BCC], squamous cell carcinoma [SCC]) [6, 65]. Mechanisms of UV-induced DNA damage underlying photocarcinogenesis include the formation of cyclobutane pyrimidine dimers (CPDs) and pyrimidine-pyrimidone (6-4) photoproducts $[32,65]$. The immunosuppressive effect of UV radiation also decreases immune surveillance against tumor formation [6]. The higher melanin content in SOC provides improved lightscattering and absorbing properties, as well as the ability to scavenge ROS generated by UV radiation and visible light $[6,50,66]$.

Consistent with findings on the photoprotective characteristics of melanin, there is lower incidence of skin cancer in SOC populations [16, 63]. Between 2014 and 2018 in the US, the age-adjusted incidence of melanoma per 100,000 individuals was 26.0 in Whites, 5.8 in American Indians/ Alaskan Natives, 4.6 in Hispanics, 1.3 in Asian/Pacific Islanders, and 1.0 in Blacks [67]. While cancer registries normally exclude data on NMSC, multiple epidemiologic studies have shown the lower incidence of NMSC in darkskinned populations $[68,69]$. Melanoma accounts for most 
deaths caused by skin cancer, which makes its early diagnosis essential. While individuals with SOC have a lower incidence of melanoma, their mortality rates are disproportionately higher than those of White individuals [70-74]. Racial and ethnic disparities in skin cancer mortality often result from delayed diagnosis, which may arise from underutilization of dermatologic care $[75,76]$ and differences in the clinical presentation of skin cancer among SOC patients. The tendency for melanoma to present in sun-protected regions in patients with SOC may delay their detection, while pigmentary variations in melanoma, BCC, and SCC may increase the likelihood of misdiagnosis $[16,77,78]$.

While the high mortality rate of melanoma in SOC has contributed to recommendations for increased sun protection in these populations $[16,63]$, the relationship between sun exposure and the development of melanoma in SOC remains unclear. A recent systematic review of 13 epidemiological studies concluded that UV exposure is not a significant risk factor for the development of melanoma in SOC, although the authors noted that the reviewed studies were of low to moderate quality [79]. The lack of association between UV exposure and the development of melanoma in studies on SOC may result from the greater proportion of acral lentiginous melanomas (ALMs) among melanomas diagnosed in these populations $[71,74,80]$. A study of the Surveillance, Epidemiology, and End Results (SEER) registry from 1986 to 2005 found that ALMs accounted for 36\%, 18\%, and $9 \%$ of melanomas diagnosed in Blacks, Asian/Pacific Islanders, and Hispanic Whites, respectively, compared with $1 \%$ of melanomas in non-Hispanic Whites [71]. Due to its similar incidence across racial/ethnic groups and tendency to develop in the relatively sun-protected palms and soles, ALM is not thought to be associated with UV radiation [16, $71,74,79]$ and instead has been linked to mechanical stress and injury [81, 82].

However, despite the greater proportion of ALMs, melanomas may still develop in sun-exposed regions among patients with SOC. In a study of 38 population-based cancer registries in the US from 1999 to 2006, melanomas of the head and neck accounted for $10.5 \%, 13.5 \%$, and $18.1 \%$ of all melanomas among Blacks, Asian/Pacific Islanders, and Hispanics, respectively [74]. Consistent with these epidemiologic observations, prior laboratory studies have also shown that melanin attenuates but does not completely prevent DNA damage from UV exposure even in the most pigmented skin types [32,83].

In contrast to melanoma, $\mathrm{BCC}$ is strongly associated with UV exposure and tends to present on the head and neck even in individuals with SOC [16, 68, 78, 84]. SCC tends to develop in the lower extremity in Black and Hispanic patients, with scarring, inflammation, and immunosuppression being the most important risk factors [16, 78]. However, studies in Asian populations have suggested an association between sun exposure and SCC [84-86]. While BCC and SCC have a significantly lower risk of metastasis and mortality than melanoma, they can be locally disfiguring and affect patients' quality of life [87]. The current recommendations for photoprotection regardless of skin type are reasonable from a standpoint of caution, but more studies are needed to clarify the reductions in incidence and mortality associated with photoprotection behaviors, if any, especially for melanoma in sun-exposed regions.

\section{Photoprotection}

Photoprotection may improve certain pigmentary disorders and prevent photoaging and photocarcinogenesis in SOC, but various survey-based studies have shown relative gaps in photoprotection behaviors among racial and ethnic groups. In the 2015 US National Health and Interview Survey (NHIS), $10.9 \%$ of non-Hispanic Blacks and $24.7 \%$ of Hispanics reported using sunscreen with an SPF of 15 or higher always or most of the time for sun protection, compared with $40.4 \%$ in non-Hispanic Whites [88]. Despite lower use of sunscreen compared with non-Hispanic Whites, the prevalence of frequent sunscreen use increased between 2000 and 2015 among both non-Hispanic Blacks (7.5-10.9\%) and Hispanics (16.9-24.7\%) [88]. Compared with non-Hispanic Whites, both non-Hispanic Blacks and Hispanics are more likely to wear sun protective clothing and seek shade, and the rates of these behaviors have increased over the past decade [88]. As a skin cancer risk behavior, indoor tanning is relatively rare in Black and Hispanic individuals in the US and its use has been declining in recent years [88, 89].

Despite promising trends in several photoprotection behaviors, studies have consistently found low use of sunscreen among non-Hispanic Blacks [90-94], Hispanics [91, 92, 94], and Asians [94, 95] relative to White individuals. In considering these statistics, it is important to note that higher rates of sunscreen use in White populations may be driven by intentional sun-seeking behavior and the desire to achieve skin tanning without burning [96]. Nevertheless, examining attitudes toward skin cancer prevention and sun protection in SOC populations may allow health professionals to optimize approaches to encourage photoprotection behaviors.

Studies using surveys and focus groups have found that individuals with SOC may underestimate the risk and preventability of skin cancer. By analyzing data from the Health Information National Trends Survey (HINTS), Buster et al. found that compared with White participants, Black participants tended to have a low perceived likelihood of developing skin cancer, and both Black and Hispanic participants were more likely to believe that skin cancer cannot be prevented [97]. Similarly, a focus group-based study by Buchanan Lunsford et al. involving 72 Black and 87 
Hispanic/Latino adults in Chicago, Miami, Atlanta, and Los Angeles observed a low perceived risk of skin cancer among participants, with negative family history and lack of exposure to the topic in their communities being major contributing factors [98]. Robinson et al. conducted focus groups in Chicago involving 40 African American, 40 Hispanic, and 40 Asian adults, and participants generally showed little concern about getting skin cancer due to not knowing family members or acquaintances affected by it [99]. Most participants in this study did not know that melanoma tends to develop on the palms and soles in SOC, which resulted in confusion about the importance of sun protection [99]. Older participants in the study also reported difficulty with self-examining the soles of their feet [99]; this may contribute to delayed detection of ALMs, especially since patients with SOC are already less likely to visit a dermatologist and receive total body skin examinations $[76,100,101]$. In the context of patient counseling, these findings highlight the importance of discussing the multifactorial nature of melanoma development, as well as how photoprotection may help prevent other conditions in SOC, such as pigmentary disorders, photoaging, and BCC.

To encourage photoprotection behaviors among patients with SOC, understanding common motivating factors is essential. Multiple survey and interview-based studies have suggested that regardless of race or ethnicity, avoidance of sunburn is a more important reason than the prevention of skin cancer in the context of sunscreen use [98, 102, 103]. However, the proportion of participants who used sunscreen to avoid sunburn was only slightly higher than that of participants who used sunscreen to prevent skin cancer among both Asian/Pacific Islanders (84.3\% vs. 83.3\%) and Hispanics $(87.9 \%$ vs. $77.4 \%)$ surveyed in the study by Mahler [102]. In contrast, less than half of Asian/Pacific Islander and Hispanic participants in this study reported using sunscreen to prevent wrinkles (36.1\% and $43.4 \%$, respectively), possibly due to their relatively young age (early to mid-20s) [102]. In the survey by Coups et al. of 787 Hispanic adults in five southern and western states in the US, more participants endorsed the benefit of avoiding sunburns than reducing skin cancer risk for sunscreen use ( $75.5 \%$ vs. $63.4 \%)$, whereas approximately equal percentages of participants endorsed these benefits for sun-protective clothing use $(72.5 \%$ vs. $71.8 \%)$ and shade seeking (60.3\% vs. $61.4 \%)$ [103]. However, fewer than half of the participants in this study endorsed that using sunscreen, seeking shade, and wearing sun protective clothing may help maintain younger-looking skin [103]. Unlike the prior two studies, Hispanic women in the focus group-based study by Buchanan Lunsford et al. reported practicing photoprotection to prevent wrinkles and skin aging, while Black participants reported practicing photoprotection to not only avoid sunburns but also to prevent worsening of skin conditions such as vitiligo, melasma, and eczema [98]. Given the potential psychological effects of photoaging and the financial costs of cosmetic treatments [104], it is important to clarify whether the low concern for wrinkles observed in some studies may reflect a lack of awareness on the possibility and cumulative nature of photoaging in SOC. The variability in reasons for photoprotection among SOC populations shown across studies is not unexpected, as they may be affected by other factors such as sex, age, socioeconomic status, and location. Reviewing all major reasons for photoprotection during patient counseling is important and will help identify barriers to this preventative measure.

Studies involving African American, Hispanic, and Asian participants have found that prevention of skin darkening is an important motivator for photoprotection $[98,99,102]$, consistent with findings that individuals in these groups are less likely to regard tanned skin as attractive $[94,105,106]$; however, views on tanning may be influenced by surrounding environments and communities. The practice of sun protection and avoidance is common across various regions in Asia, such as Korea, Taiwan, China, and Japan, and this has been attributed to a traditional aesthetic preference for fair skin, particularly among Asian women [39, 85, 105-107]. In contrast, acculturation to Euro-American communities has been associated with greater preference for tanned skin, increased sun-seeking behaviors, and decreased practice of sun protection in individuals of Asian descent [108-110]. Among Hispanics, acculturation with norms in the US have also been associated with a decreased likelihood of seeking shade and wearing sun protective clothing [111-113]. These findings show the importance of considering not only patients' skin type but also their personal values, culture, and environment when discussing photoprotection behaviors.

Recognizing and addressing barriers may help to encourage photoprotection among patients with SOC. Using surveys on sunscreen use, Mahler found that the most common reasons for failing to use sunscreen among Asian/Pacific Islanders and Hispanics included forgetting to apply it, followed by a dislike of its greasiness; whereas one-third of Hispanics noted that sunscreen is too greasy, over half of the Asian participants in the study had this concern [102]. Similar barriers to sunscreen use were reported by Black participants in focus groups [98]. Concerns for greasiness may arise from the use of physical sunscreens based on inorganic filters (e.g., titanium dioxide, zinc oxide), which not only tend to be thick and oily but also leave white residue that may be cosmetically unacceptable for darker-skinned individuals $[114,115]$. Due to recent concerns that the application of sunscreen at recommended levels may lead to systemic absorption [116], titanium dioxide and zinc oxide are the only ingredients that are generally recognized as safe and effective (GRASE) by the US FDA [115]. Chemical sunscreens with organic filters and transparent formulations 
are often marketed to individuals with SOC [117], which may address some of the previously mentioned barriers to sunscreen use, but more studies are needed to verify their safety under current FDA provisions [118]. Oral photoprotection agents such as Polypodium leucotomos extract, nicotinamide, and sulforaphane are also currently being investigated as adjunctive agents to decrease skin photodamage [119-122], and future studies may explore their use in SOC populations.

\section{Recommending Photoprotection for Skin of Color}

Despite their decreased risk of sunburns, photoaging, and photocarcinogenesis, we suggest that patients with darker skin still practice multimodal photoprotection behaviors routinely (Table 1 ), in line with previously published recommendations $[16,63,64]$, due to the association of sun exposure with pigmentary disorders, photoaging, and BCC in SOC. Patients should use sunscreens that are broad spectrum (i.e., protects against UVA and UVB radiation), water resistant, and with an SPF of 30 or higher. To allow adequate photoprotection, sunscreen should be applied at $2 \mathrm{mg} / \mathrm{cm}^{2}$, which may be estimated with the teaspoon rule [123, 124], at $15 \mathrm{~min}$ before sun exposure and every $2 \mathrm{~h}$ afterwards. Physical sunscreens with non-micronized inorganic filters (e.g., titanium dioxide, zinc oxide) may protect against UV radiation and visible light, but the thick texture and significant white hue of many formulations (when applied at the recommended amount) make them impractical in darkerskinned individuals. Tinted sunscreens, which provide protection against both UV radiation and visible light, is a potential alternative considering that different shades may be available for individuals with SOC [44]. Patients seeking transparent formulations may consider using sunscreens with nanosized inorganic filters or organic filters, although these do not provide protection against visible light. Despite the possibility for systemic absorption and the need for additional safety data on chemical sunscreens based on organic filters, the FDA has cautioned against discontinuing their use [116, 118].

Besides applying sunscreen, patients may also wear hats and sun-protective clothing (e.g., long-sleeved shirt, pants) to decrease the area of sun-exposed skin. This is especially important in this population given the aforementioned limitations associated with sunscreens. Commercial clothing may have inadequate UV protection factor (UPF), and patients should use sun-protective clothing labeled with UPF of 40 or higher to provide additional photoprotection $[125,126]$. In general, patients with SOC are more likely to wear sun-protective clothing and seek shade compared with White individuals, and these photoprotection behaviors should continue to be encouraged since they have been shown to be more effective at preventing sunburns than sunscreen [127, 128], likely due to increased duration of sun exposure among those using sunscreen [129]. The use of umbrellas for sun protection is common in East Asian countries [39, 85, 105-107], and its social acceptability has also been found to be moderate in a cross-sectional survey of 382 women in Atlanta, supporting its use as an adjunctive form of a photoprotection method [130]. The increased wearing of masks while outdoors due to the coronavirus disease 2019 (COVID-19) pandemic has also likely allowed increased photoprotection of the face [131].

For both patients and health professionals, vitamin D deficiency is a common concern when discussing photoprotection for SOC. National data in the US have shown racial and ethnic disparities in the prevalence of vitamin D deficiency, affecting Hispanics and particularly Black individuals $[132,133]$. However, whether photoprotection behaviors may affect the likelihood of vitamin D deficiency has been unclear. Prior reviews of the literature have suggested that sunscreen use is not associated with a significant decrease in serum vitamin D levels [134-136], but most studies to date have been conducted in light-skinned participants. A study of National Health and Nutrition Examination Survey (NHANES) data from 2003 to 2006 by Linos et al. found that while Hispanics and Blacks had lower 25-hydroxyvitamin D [25(OH)D] levels compared with Whites on average, the practice of photoprotection behaviors, including staying

Table 1 Recommendations for photoprotection in individuals with skin of color

\section{Recommendations}

Apply broad spectrum sunscreen with SPF of 30 or higher at $2 \mathrm{mg} / \mathrm{cm}^{2} 15 \mathrm{~min}$ before sun exposure and every $2 \mathrm{~h}$ afterwards

Tinted sunscreens and sunscreens based on non-micronized inorganic filters are preferred for protection against both UV radiation and visible light

Sunscreens with nanosized inorganic filters or organic filters are suitable options if transparent formulations are desired, but they protect against UV radiation and not visible light

Wear hats, sunglasses, and sun-protective clothing (e.g., long-sleeved shirt, pants) with UPF of 40 or higher

Seek shade and avoid sun exposure during peak daylight hours

$S P F$ sun protection factor, $U P F \mathrm{UV}$ protection factor, $U V$ ultraviolet 
in the shade, wearing long sleeves, wearing a hat, and using sunscreen, were not associated with a significant decrease in 25(OH)D levels in Hispanics and Blacks [137]. In fact, sunscreen use was associated with increased $25(\mathrm{OH}) \mathrm{D}$ levels among Black participants [137], possibly due to increased sun exposure or insufficient application/reapplication of sunscreen. More studies are needed to examine the relationship between photoprotection behaviors and vitamin D levels in other contexts and SOC populations.

Deliberate sun exposure or indoor tanning, even if practiced to increase vitamin D levels, is not recommended due to the difficulty and impracticality of maintaining a safe level of UV exposure for vitamin D synthesis among patients. Instead, we recommend that individuals with SOC follow the National Academy of Medicine's (formerly called the Institute of Medicine) recommended dietary vitamin D intake (400 IU/day between 0 and 12 months of age, $600 \mathrm{IU} /$ day between 1 and 70 years of age, and $800 \mathrm{IU} /$ day above 70 years of age), which may be achieved through the consumption of natural food sources, vitamin D-fortified products, and supplements [138]. Importantly, these recommended intake values were developed based on the assumption of little to no sun exposure and accounts for variations in vitamin D synthesis due to skin pigmentation [138].

The use of photosensitizing drugs may also increase patients' susceptibility to skin photodamage, and drugs that have been implicated include tetracycline, doxycycline, hydrochlorothiazide (HCTZ), amiodarone, naproxen, piroxicam, chlorpromazine, and thioridazine, among others [139]. The US FDA recently approved a label change for HCTZ to recommend increased photoprotection among patients taking the drug, due to its association with drug-induced photosensitivity and increased risk of developing NMSC, particularly SCC [140]. Since thiazide diuretics are commonly recommended as first-line treatment for hypertension in Black patients [141, 142], they may have an increased risk of developing skin photodamage due to HCTZ use. We previously found increased susceptibility to recent sunburn in non-Hispanic Black patients taking HCTZ, particularly among non-Hispanic Black women [143], which shows the importance of inquiring and counseling on photoprotection behaviors in these populations.

\section{Conclusion}

Current recommendations for patients with SOC to practice sun protection are complicated by areas in need of further study, including the relationship between sun exposure and melanoma in SOC, as well as the extent to which individual photoprotection behaviors may affect vitamin D levels. These uncertainties should be conveyed when discussing sun protection and avoidance with patients, along with the well-established consequences of sun exposure in SOC, such as dyspigmentation, photoaging, and BCC. Appearance-based interventions have been shown to promote photoprotection behaviors [144, 145], and their utility in comparison with health-based approaches will depend on individual patient's concerns and priorities. While the findings discussed in this review article are not generalizable to all SOC populations and geographic regions, they highlight the unique considerations and challenges to photoprotection that need to be further examined. As we learn more, counseling remains the critical piece in SOC patients [146, 147] and this will only become more important as the relative sizes of SOC populations continue to increase over the next decades in the US [148].

\section{Declarations}

Funding No sources of funding were used to assist in the preparation of this article.

Conflict of interest Jerry Tsai and Anna L. Chien have declared no conflicts of interest.

Ethics approval Not applicable.

Consent to participate Not applicable.

Consent to publish Not applicable.

Availability of data and material Not applicable.

Code availability Not applicable.

Author contributions All authors contributed to the conceptualization, drafting, and revision of this manuscript.

\section{References}

1. American Academy of Dermatology. Prevent skin cancer. 2021. https://www.aad.org/public/diseases/skin-cancer/prevent/how. Cited 1 Oct 2021.

2. Anderson RR, Parrish JA. The optics of human skin. J Investig Dermatol. 1981;77(1):13-9.

3. Stamatas GN, Zmudzka BZ, Kollias N, Beer JZ. Non-invasive measurements of skin pigmentation in situ. Pigment Cell Res. 2004;17(6):618-26.

4. Quevedo WC, Fitzpatrick TB, Pathak MA, Jimbow K. Role of light in human skin color variation. Am J Phys Anthropol. 1975;43(3):393-408.

5. Jablonski NG, Chaplin G. The evolution of human skin coloration. J Hum Evol. 2000;39(1):57-106.

6. Brenner M, Hearing VJ. The protective role of melanin against UV damage in human skin. Photochem Photobiol. 2008;84(3):539-49.

7. Fitzpatrick TB. The validity and practicality of sun-reactive skin types I through VI. Arch Dermatol. 1988;124(6):869.

8. Rünger TM, et al. Cutaneous photobiology. In: Kang S, Amagai M, Bruckner AL, Enk AH, Margolis DJ, McMichael AJ, et al., 
editors. Fitzpatrick's dermatology. 9th ed. New York: McGrawHill Education; 2019.

9. Chan JL, Ehrlich A, Lawrence RC, Moshell AN, Turner ML, Kimball AB. Assessing the role of race in quantitative measures of skin pigmentation and clinical assessments of photosensitivity. J Am Acad Dermatol. 2005;52(4):609-15.

10. Chardon A, Cretois I, Hourseau C. Skin colour typology and suntanning pathways. Int J Cosmet Sci. 1991;13(4):191-208.

11. Ly BCK, Dyer EB, Feig JL, Chien AL, Del Bino S. Research techniques made simple: cutaneous colorimetry: a reliable technique for objective skin color measurement. J Investig Dermatol. 2020;140(1):3-12 e1.

12. Pershing LK, Tirumala VP, Nelson JL, Corlett JL, Lin AG, Meyer LJ, et al. Reflectance spectrophotometer: the dermatologists' sphygmomanometer for skin phototyping? J Investig Dermatol. 2008;128(7):1633-40.

13. Eilers S, Bach DQ, Gaber R, Blatt H, Guevara Y, Nitsche K, et al. Accuracy of self-report in assessing fitzpatrick skin phototypes I through VI. JAMA Dermatol. 2013;149(11):1289.

14. Tsai J, Chien AL, Kang JU, Leung S, Kang S, Garza LA. Hyperspectral measurement of skin reflectance detects differences in the visible and near-infrared regions according to race, gender and body site. J Eur Acad Dermatol Venereol. 2021;35(5):e330-3.

15. Taylor SC. Skin of color: biology, structure, function, and implications for dermatologic disease. J Am Acad Dermatol. 2002;46(2 Suppl Understanding):S41-62.

16. Agbai ON, Buster K, Sanchez M, Hernandez C, Kundu RV, Chiu $\mathrm{M}$, et al. Skin cancer and photoprotection in people of color: a review and recommendations for physicians and the public. J Am Acad Dermatol. 2014;70(4):748-62.

17. Schwartz RS. Racial profiling in medical research. N Engl J Med. 2001;344(18):1392-3.

18. United States Census Bureau. About Race. October 16, 2020. https://www.census.gov/topics/population/race/about.html. Cited 6 Sept 2021.

19. He SY, McCulloch CE, Boscardin WJ, Chren MM, Linos E, Arron ST. Self-reported pigmentary phenotypes and race are significant but incomplete predictors of Fitzpatrick skin phototype in an ethnically diverse population. J Am Acad Dermatol. 2014;71(4):731-7.

20. Chung JH, Koh WS, Youn JI. Relevance of skin phototyping to a Korean population. Clin Exp Dermatol. 1994;19(6):476-8.

21. Youn JI, Oh JK, Kim BK, Suh DH, Chung JH, Oh SJ, et al. Relationship between skin phototype and MED in Korean, brown skin. Photodermatol Photoimmunol Photomed. 1997;13(5-6):208-11.

22. Sanclemente G, Zapata J-F, García J-J, Gaviria Á, Gómez L-F, Barrera M. Lack of correlation between minimal erythema dose and skin phototype in a colombian scholar population. Skin Res Technol. 2008;14(4):403-9.

23. Rawlings AV. Ethnic skin types: are there differences in skin structure and function?1. Int J Cosmet Sci. 2006;28(2):79-93.

24. Alaluf S, Atkins D, Barrett K, Blount M, Carter N, Heath A. Ethnic variation in melanin content and composition in photoexposed and photoprotected human skin. Pigment Cell Res. 2002;15(2):112-8.

25. Szabó G, Gerald AB, Pathak MA, Fitzpatrick TB. Racial differences in the fate of melanosomes in human epidermis. Nature. 1969;222(5198):1081-2.

26. Tadokoro T, Yamaguchi Y, Batzer J, Coelho SG, Zmudzka BZ, Miller SA, et al. Mechanisms of skin tanning in different racial/ ethnic groups in response to ultraviolet radiation. J Investig Dermatol. 2005;124(6):1326-32.
27. Kollias N, Sayre RM, Zeise L, Chedekel MR. New trends in photobiology: photoprotection by melanin. J Photochem Photobiol B. 1991;9(2):135-60.

28. Thong H-Y, Jee S-H, Sun C-C, Boissy RE. The patterns of melanosome distribution in keratinocytes of human skin as one determining factor of skin colour. Br J Dermatol. 2003;149(3):498-505.

29. Kaidbey KH, Agin PP, Sayre RM, Kligman AM. Photoprotection by melanin - a comparison of black and Caucasian skin. J Am Acad Dermatol. 1979;1(3):249-60.

30. Wagner JK, Parra EJ, Norton LH, Jovel C, Shriver MD. Skin responses to ultraviolet radiation: effects of constitutive pigmentation, sex, and ancestry. Pigment Cell Res. 2002;15(5):385-90.

31. Rijken F, Bruijnzeel PLB, Van Weelden H, Kiekens RCM. Responses of black and white skin to solar-simulating radiation: differences in DNA photodamage, infiltrating neutrophils, proteolytic enzymes induced, keratinocyte activation, and IL-10 expression. J Investig Dermatol. 2004;122(6):1448-55.

32. Tadokoro T, Kobayashi N, Zmudzka BZ, Ito S, Wakamatsu K, Yamaguchi Y, et al. UV-induced DNA damage and melanin content in human skin differing in racial/ethnic origin. FASEB J. 2003;17(9):1177-9.

33. Scott G, Rodriguez-Burford C, Seiberg M, Han R, Babiarz L, Grizzle W, et al. Protease-activated receptor 2, a receptor involved in melanosome transfer, is upregulated in human skin by ultraviolet irradiation. J Investig Dermatol. 2001;117(6):1412-20.

34. Babiarz-Magee L, Chen N, Seiberg M, Lin CB. The expression and activation of protease-activated receptor-2 correlate with skin color. Pigment Cell Res. 2004;17(3):241-51.

35. Austin E, Geisler AN, Nguyen J, Kohli I, Hamzavi I, Lim HW, et al. Visible light. Part I: Properties and cutaneous effects of visible light. J Am Acad Dermatol. 2021;84(5):1219-31.

36. Geisler AN, Austin E, Nguyen J, Hamzavi I, Jagdeo J, Lim HW. Visible light. Part II: photoprotection against visible and ultraviolet light. J Am Acad Dermatol. 2021;84(5):1233-44.

37. Kaufman BP, Aman T, Alexis AF. Postinflammatory hyperpigmentation: epidemiology, clinical presentation, pathogenesis and treatment. Am J Clin Dermatol. 2018;19(4):489-503.

38. Halder RM, Nootheti PK. Ethnic skin disorders overview. J Am Acad Dermatol. 2003;48(6):S143-8.

39. Chung JH. Photoaging in Asians. Photodermatol Photoimmunol Photomed. 2003;19(3):109-21.

40. Harumi O, Goh CL. The effect of melasma on the quality of life in a sample of women living in Singapore. J Clin Aesthet Dermatol. 2016;9(1):21-4.

41. Freitag F, Cestari T, Leopoldo L, Paludo P, Boza J. Effect of melasma on quality of life in a sample of women living in southern Brazil. J Eur Acad Dermatol Venereol. 2008;22(6):655-62.

42. Alexis AF, Sergay AB, Taylor SC. Common dermatologic disorders in skin of color: a comparative practice survey. Cutis. 2007;80(5):387-94.

43. Konda S, Geria AN, Halder RM. New horizons in treating disorders of hyperpigmentation in skin of color. Semin Cutan Med Surg. 2012;31(2):133-9.

44. Lyons AB, Trullas C, Kohli I, Hamzavi IH, Lim HW. Photoprotection beyond ultraviolet radiation: a review of tinted sunscreens. J Am Acad Dermatol. 2021;84(5):1393-7.

45. Gilchrest BA. Photoaging. J Investig Dermatol. 2013;133:E2-6.

46. Han A, Chien AL, Kang S. Photoaging. Dermatol Clin. 2014;32(3):291-9.

47. Huang AH, Chien AL. Photoaging: a review of current literature. Curr Derm Rep. 2020;9(1):22-9.

48. Battie C, Jitsukawa S, Bernerd F, Del Bino S, Marionnet C, Verschoore $\mathrm{M}$. New insights in photoaging, UVA induced damage and skin types. Exp Dermatol. 2014;23:7-12. 
49. Fisher GJ, Kang S, Varani J, Bata-Csorgo Z, Wan Y, Datta S, et al. Mechanisms of photoaging and chronological skin aging. Arch Dermatol. 2002;138(11):1462-70.

50. Liebel F, Kaur S, Ruvolo E, Kollias N, Southall MD. Irradiation of skin with visible light induces reactive oxygen species and matrix-degrading enzymes. J Investig Dermatol. 2012;132(7):1901-7.

51. Varani J, Spearman D, Perone P, Fligiel SEG, Datta SC, Wang $\mathrm{ZQ}$, et al. Inhibition of type I procollagen synthesis by damaged collagen in photoaged skin and by collagenase-degraded collagen in vitro. Am J Pathol. 2001;158(3):931-42.

52. Goh SH. The treatment of visible signs of senescence: the Asian experience. Br J Dermatol. 1990;122(s35):105-9.

53. Nouveau-Richard S, Yang Z, Mac-Mary S, Li L, Bastien P, Tardy I, et al. Skin ageing: a comparison between Chinese and European populations. J Dermatol Sci. 2005;40(3):187-93.

54. Vashi NA, de Castro Maymone MB, Kundu RV. Aging differences in ethnic skin. J Clin Aesthet Dermatol. 2016;9(1):31-8.

55. Venkatesh S, Maymone MBC, Vashi NA. Aging in skin of color. Clin Dermatol. 2019;37(4):351-7.

56. Hernández-Pérez E, Ibiett EV. Gross and microscopic findings in patients submitted to nonablative full-face resurfacing using intense pulsed light: a preliminary study. Dermatol Surg. 2002;28(8):651-5.

57. Young AL, Levy S, Nighland M, Grossman R, Silvers DN, Celebi JT. Are dark-skinned people really protected from ultraviolet radiation? Clin Exp Dermatol. 2010;35(4):392-6.

58. Langton AK, Alessi S, Hann M, Chien AL, Kang S, Griffiths CEM, et al. Aging in skin of color: disruption to elastic fiber organization is detrimental to skin's biomechanical function. $\mathrm{J}$ Investig Dermatol. 2019;139(4):779-88.

59. Chung JH, Lee SH, Youn CS, Park BJ, Kim KH, Park KC, et al. Cutaneous photodamage in Koreans: influence of sex, sun exposure, smoking, and skin color. Arch Dermatol. 2001;137(8):1043-51.

60. Griffiths CEM. A Photonumeric scale for the assessment of cutaneous photodamage. Arch Dermatol. 1992;128(3):347.

61. Larnier C, Ortonne J-P, Venot A, Faivre B, Beani J-C, Thomas P, et al. Evaluation of cutaneous photodamage using a photographic scale. Br J Dermatol. 1994;130(2):167-73.

62. Chien AL, Qi J, Grandhi R, Kim N, Cesar SSA, Harris-Tryon $\mathrm{T}$, et al. Effect of age, gender, and sun exposure on ethnic skin photoaging: evidence gathered using a new photonumeric scale. J Natl Med Assoc. 2018;110(2):176-81.

63. Cestari T, Buster K. Photoprotection in specific populations: children and people of color. J Am Acad Dermatol. 2017;76(3):S110-21.

64. Passeron T, Lim HW, Goh CL, Kang HY, Ly F, Morita A, et al. Photoprotection according to skin phototype and dermatoses: practical recommendations from an expert panel. J Eur Acad Dermatol Venereol. 2021;35(7):1460-9.

65. Subhadarshani S, Athar M, Elmets CA. Photocarcinogenesis. Curr Derm Rep. 2020;9(3):189-99.

66. Bustamante J, Bredeston L, Malanga G, Mordoh J. Role of melanin as a scavenger of active oxygen species. Pigment Cell Res. 1993;6(5):348-53

67. U.S. Cancer Statistics Working Group. U.S. cancer statistics data visualizations tool, based on 2020 submission data (1999-2018). 2021. http://www.cdc.gov/cancer/dataviz. Cited 20 Sept 2021.

68. Gloster HM, Neal K. Skin cancer in skin of color. J Am Acad Dermatol. 2006;55(5):741-60.

69. Lomas A, Leonardi-Bee J, Bath-Hextall F. A systematic review of worldwide incidence of nonmelanoma skin cancer. Br J Dermatol. 2012;166(5):1069-80.

70. Qian Y, Johannet P, Sawyers A, Yu J, Osman I, Zhong J. The ongoing racial disparities in melanoma: an analysis of the surveillance, epidemiology, and end results database (19752016). J Am Acad Dermatol. 2021;84(6):1585-93.

71. Bradford PT, Goldstein AM, Mcmaster ML, Tucker MA. Acral lentiginous melanoma: incidence and survival patterns in the United States, 1986-2005. Arch Dermatol. 2009;145(4):427-34.

72. Siegel RL, Miller KD, Fuchs HE, Jemal A. Cancer Statistics, 2021. CA Cancer J Clin. 2021;71(1):7-33.

73. Zell JA, Cinar P, Mobasher M, Ziogas A, Meyskens FL, AntonCulver H. Survival for patients with invasive cutaneous melanoma among ethnic groups: the effects of socioeconomic status and treatment. J Clin Oncol. 2008;26(1):66-75.

74. Wu X-C, Eide MJ, King J, Saraiya M, Huang Y, Wiggins C, et al. Racial and ethnic variations in incidence and survival of cutaneous melanoma in the United States, 1999-2006. J Am Acad Dermatol. 2011;65(5):S26.e1-S.e13.

75. Buster KJ, Stevens EI, Elmets CA. Dermatologic health disparities. Dermatol Clin. 2012;30(1):53-9.

76. Tripathi R, Knusel KD, Ezaldein HH, Scott JF, Bordeaux JS. Association of demographic and socioeconomic characteristics with differences in use of outpatient dermatology services in the United States. JAMA Dermatol. 2018;154(11):1286.

77. Higgins S, Nazemi A, Chow M, Wysong A. Review of nonmelanoma skin cancer in African Americans, Hispanics, and Asians. Dermatol Surg. 2018;44(7):903-10.

78. Hogue L, Harvey VM. Basal cell carcinoma, squamous cell carcinoma, and cutaneous melanoma in skin of color patients. Dermatol Clin. 2019;37(4):519-26.

79. Lopes FCPS, Sleiman MG, Sebastian K, Bogucka R, Jacobs EA, Adamson AS. UV exposure and the risk of cutaneous melanoma in skin of color. JAMA Dermatol. 2021;157(2):213.

80. Cress RD, Holly EA. Incidence of cutaneous melanoma among non-Hispanic Whites, Hispanics, Asians, and Blacks: an analysis of California Cancer Registry data, 1988-93. Cancer Causes Control. 1997;8(2):246-52.

81. Basurto-Lozada P, Molina-Aguilar C, Castaneda-Garcia C, Vázquez-Cruz ME, Garcia-Salinas OI, Álvarez-Cano A, et al. Acral lentiginous melanoma: Basic facts, biological characteristics and research perspectives of an understudied disease. Pigment Cell Melanoma Res. 2021;34(1):59-71.

82. Lee JH, Choi YD, Hwang JH, Shin M-H, Yun SJ. Frequency of trauma, physical stress, and occupation in acral melanoma: analysis of 313 acral melanoma patients in Korea. Ann Dermatol. 2021;33(3):228.

83. Del Bino S, Bernerd F. Variations in skin colour and the biological consequences of ultraviolet radiation exposure. Br J Dermatol. 2013;169:33-40.

84. Oh CC, Jin A, Koh W-P. Trends of cutaneous basal cell carcinoma, squamous cell carcinoma, and melanoma among the Chinese, Malays, and Indians in Singapore from 1968-2016. JAAD Int. 2021;4:39-45.

85. Chen Y-C, Christiani DC, Su H-JJ, Hsueh Y-M, Smith TJ, Ryan LM, et al. Early-life or lifetime sun exposure, sun reaction, and the risk of squamous cell carcinoma in an Asian population. Cancer Causes Control. 2010;21(5):771-6.

86. Kato H, Oda T, Watanabe S, Morita A. Facial distribution of squamous cell carcinoma in Japanese. Exp Dermatol. 2019;28:72-4.

87. Weinstock MA. Nonmelanoma skin cancer mortality. Arch Dermatol. 1991;127(8):1194.

88. National Cancer Institute. Cancer trends progress report. 2021. https://progressreport.cancer.gov. Cited 28 Sept 2021.

89. Guy GP Jr, Watson M, Seidenberg AB, Hartman AM, Holman DM, Perna F. Trends in indoor tanning and its association with sunburn among US adults. J Am Acad Dermatol. 2017;76(6):1191-3. 
90. Pichon LC, Corral I, Landrine H, Mayer JA, Norman GJ. Sunprotection behaviors among African Americans. Am J Prev Med. 2010;38(3):288-95.

91. Buller DB, Cokkinides V, Hall HI, Hartman AM, Saraiya M, Miller E, et al. Prevalence of sunburn, sun protection, and indoor tanning behaviors among Americans: review from national surveys and case studies of 3 states. J Am Acad Dermatol. 2011;65(5):S114.e1-S.e1.

92. Summers P. Sunscreen use: non-hispanic blacks compared with other racial and/or ethnic groups. Arch Dermatol. 2011;147(7):863.

93. Holman DM, Berkowitz Z, Guy GP Jr, Hawkins NA, Saraiya M, Watson M. Patterns of sunscreen use on the face and other exposed skin among US adults. J Am Acad Dermatol. 2015;73(1):83-92 e1.

94. Calderón TA, Bleakley A, Jordan AB, Lazovich D, Glanz K. Correlates of sun protection behaviors in racially and ethnically diverse U.S. adults. Prev Med Rep. 2019;13:346-53.

95. Martin A, Liu J, Thatiparthi A, Ge S, Wu JJ. Asian Americans are less likely to wear sunscreen compared with non-Hispanic whites. J Am Acad Dermatol. 2022;86(1):167-9.

96. Autier P. Sunscreen abuse for intentional sun exposure. Br J Dermatol. 2009;161:40-5.

97. Buster KJ, You Z, Fouad M, Elmets C. Skin cancer risk perceptions: a comparison across ethnicity, age, education, gender, and income. J Am Acad Dermatol. 2012;66(5):771-9.

98. Buchanan Lunsford N, Berktold J, Holman DM, Stein K, Prempeh A, Yerkes A. Skin cancer knowledge, awareness, beliefs and preventive behaviors among black and hispanic men and women. Prev Med Rep. 2018;12:203-9.

99. Robinson JK, Joshi KM, Ortiz S, Kundu RV. Melanoma knowledge, perception, and awareness in ethnic minorities in Chicago: recommendations regarding education. Psychooncology. 2011;20(3):313-20.

100. Lingala B, Li S, Wysong A, Truong AK, Kim D, Chang ALS. Low rate of dermatology outpatient visits in Asian-Americans: an initial survey study for associated patient-related factors. BMC Dermatol. 2014;14(1):13.

101. Korta DZ, Saggar V, Wu TP, Sanchez M. Racial differences in skin cancer awareness and surveillance practices at a public hospital dermatology clinic. J Am Acad Dermatol. 2014;70(2):312-7.

102. Mahler HIM. Reasons for using and failing to use sunscreen: comparison among whites, Hispanics, and Asian/Pacific Islanders in Southern California. JAMA Dermatol. 2014;150(1):90.

103. Coups EJ, Stapleton JL, Manne SL, Hudson SV, Medina-Forrester A, Rosenberg SA, et al. Psychosocial correlates of sun protection behaviors among U.S. Hispanic adults. J Behav Med. 2014;37(6):1082-90.

104. Taylor CR, Stern RS, Leyden JJ, Gilchrest BA. Photoaging/ photodamage and photoprotection. J Am Acad Dermatol. 1990;22(1):1-15.

105. Cheng S, Lian S, Hao Y, Kang N, Li S, Nie Y, et al. Sun-exposure knowledge and protection behavior in a North Chinese population: a questionnaire-based study. Photodermatol Photoimmunol Photomed. 2010;26(4):177-81.

106. Yan S, Xu F, Yang C, Li F, Fan J, Wang L, et al. Demographic differences in sun protection beliefs and behavior: a communitybased study in Shanghai, China. Int J Environ Res Public Health. 2015;12(3):3232-45.

107. $\mathrm{Ng} \mathrm{W}$. Use of sun-protective items by Japanese pedestrians. Arch Dermatol. 2011;147(10):1167.

108. Gorell E, Lee C, Muñoz C, Chang ALS. Adoption of western culture by Californian Asian Americans. Arch Dermatol. 2009;145(5):552-6.
109. Bowers JM, Hamilton JG, Wu YP, Moyer A, Hay JL. Acculturation, sun tanning behavior, and tanning attitudes among Asian college students in the Northeastern USA. Int J Behav Med. 2021. https://doi.org/10.1007/s12529-021-09993-x (Epub 4 May 2021).

110. Chen H-Y, Robinson JK, Jablonski NG. A cross-cultural exploration on the psychological aspects of skin color aesthetics: implications for sun-related behavior. Transl Behav Med. 2020;10(1):234-43.

111. Andreeva VA, Unger JB, Yaroch AL, Cockburn MG, BaezcondeGarbanati L, Reynolds KD. Acculturation and sun-safe behaviors among US Latinos: findings from the 2005 Health Information National Trends Survey. Am J Public Health. 2009;99(4):734-41.

112. Coups EJ, Stapleton JL, Hudson SV, Medina-Forrester A, NatalePereira A, Goydos JS. Sun protection and exposure behaviors among Hispanic adults in the United States: differences according to acculturation and among Hispanic subgroups. BMC Public Health. 2012;12(1):985.

113. Coups EJ, Stapleton JL, Hudson SV, Medina-Forrester A, Rosenberg SA, Gordon MA, et al. Linguistic acculturation and skin cancer-related behaviors among hispanics in the Southern and Western United States. JAMA Dermatol. 2013;149(6):679.

114. Xu S, Kwa M, Agarwal A, Rademaker A, Kundu RV. Sunscreen product performance and other determinants of consumer preferences. JAMA Dermatol. 2016;152(8):920.

115. Guan LL, Lim HW, Mohammad TF. Sunscreens and photoaging: a review of current literature. Am J Clin Dermatol. 2021;22(6):819-28.

116. Matta MK, Zusterzeel R, Pilli NR, Patel V, Volpe DA, Florian J, et al. Effect of sunscreen application under maximal use conditions on plasma concentration of sunscreen active ingredients. JAMA. 2019;321(21):2082.

117. Song H, Beckles A, Salian P, Porter ML. Sunscreen recommendations for patients with skin of color in the popular press and in the dermatology clinic. Int J Womens Dermatol. 2021;7(2):165-70.

118. US Food and Drug Administration. FDA advances new proposed regulation to make sure that sunscreens are safe and effective. 2019. https://www.fda.gov/news-events/press-announcements/ fda-advances-new-proposed-regulation-make-sure-sunscreensare-safe-and-effective. Cited 1 Oct 2021

119. Chen AC, Damian DL, Halliday GM. Oral and systemic photoprotection. Photodermatol Photoimmunol Photomed. 2014;30(2-3):102-11.

120. Lim HW, Arellano-Mendoza M-I, Stengel F. Current challenges in photoprotection. J Am Acad Dermatol. 2017;76(3):S91-9.

121. Middelkamp-Hup MA, Pathak MA, Parrado C, Goukassian D, Rius-Diaz F, Mihm MC, et al. Oral Polypodium leucotomos extract decreases ultraviolet-induced damage of human skin. J Am Acad Dermatol. 2004;51(6):910-8.

122. Talalay P, Fahey JW, Healy ZR, Wehage SL, Benedict AL, Min $\mathrm{C}$, et al. Sulforaphane mobilizes cellular defenses that protect skin against damage by UV radiation. Proc Natl Acad Sci. 2007;104(44):17500-5.

123. Isedeh P, Osterwalder U, Lim HW. Teaspoon rule revisited: proper amount of sunscreen application. Photodermatol Photoimmunol Photomed. 2013;29(1):55-6.

124. Schneider J. The teaspoon rule of applying sunscreen. Arch Dermatol. 2002;138(6):838-9.

125. Gambichler T, Altmeyer P, Hoffmann K. Role of clothes in sun protection. Cancers of the skin. Berlin: Springer; 2002. p. 15-25.

126. Wang SQ, Balagula Y, Osterwalder U. Photoprotection: a review of the current and future technologies. Dermatol Ther. 2010;23(1):31-47.

127. Linos E, Keiser E, Fu T, Colditz G, Chen S, Tang JY. Hat, shade, long sleeves, or sunscreen? Rethinking US sun protection 
messages based on their relative effectiveness. Cancer Causes Control. 2011;22(7):1067-71.

128. Patel SP, Chien AL. Sun protective clothing and sun avoidance: the most critical components of photoprotection in patients with melanoma. Dermatol Surg. 2021;47(3):333-7.

129. Autier P, Boniol M, Doré J-F. Sunscreen use and increased duration of intentional sun exposure: still a burning issue. Int J Cancer. 2007;121(1):1-5.

130. McMichael JR, Ezirike J, Veledar E, Rice JE, Chen SC. The social acceptability of handheld umbrellas for sun protection. Photodermatol Photoimmunol Photomed. 2014;30(4):220-7.

131. Doyon VC, Khosravi-Hafshejani T, Richer V. An added benefit of masks during the COVID-19 pandemic: ultraviolet protection. J Cutan Med Surg. https://doi.org/10.1177/1203475421103447 (Epub 28 Jul 2021)

132. Ginde AA, Liu MC, Camargo CA. Demographic differences and trends of vitamin D insufficiency in the US population, 19882004. Arch Intern Med. 2009;169(6):626.

133. US Centers for Disease Control and Prevention. Second national report on biochemical indicators of diet and nutrition in the U.S. Population 2012. Atlanta, GA: National Center for Environmental Health; 2012.

134. Norval M, Wulf HC. Does chronic sunscreen use reduce vitamin D production to insufficient levels? Br J Dermatol. 2009;161(4):732-6.

135. Kannan S, Lim HW. Photoprotection and vitamin D: a review. Photodermatol Photoimmunol Photomed. 2014;30(2-3):137-45.

136. Passeron T, Bouillon R, Callender V, Cestari T, Diepgen TL, Green AC, et al. Sunscreen photoprotection and vitamin D status. Br J Dermatol. 2019;181(5):916-31.

137. Linos E, Keiser E, Kanzler M, Sainani KL, Lee W, Vittinghoff E, et al. Sun protective behaviors and vitamin D levels in the US population: NHANES 2003-2006. Cancer Causes Control. 2012;23(1):133-40.

138. Institute of Medicine, Food and Nutrition Board. Dietary reference intakes for calcium and vitamin D. Washington, DC: National Academy Press; 2011.

139. Blakely KM, Drucker AM, Rosen CF. Drug-induced photosensitivity - an update: culprit drugs, prevention and management. Drug Saf. 2019;42(7):827-47.
140. US Food and Drug Administration. FDA approves label changes to hydrochlorothiazide to describe small risk of non-melanoma skin cancer. 2020. https://www.fda.gov/drugs/drug-safety-andavailability/fda-approves-label-changes-hydrochlorothiazidedescribe-small-risk-non-melanoma-skin-cancer. Cited 14 Sept 2020.

141. Whelton PK, Carey RM, Aronow WS, Casey DE, Collins KJ, Dennison, et al. 2017 ACC/AHA/AAPA/ABC/ACPM/AGS/ $\mathrm{APhA} / \mathrm{ASH} / \mathrm{ASPC} / \mathrm{NMA} / \mathrm{PCNA}$ Guideline for the prevention, detection, evaluation, and management of high blood pressure in adults: a report of the American College of Cardiology/American Heart Association Task Force on clinical practice guidelines. Hypertension. 2018;71(6):e13-15.

142. James PA, Oparil S, Carter BL, Cushman WC, DennisonHimmelfarb C, Handler J, et al. 2014 evidence-based guideline for the management of high blood pressure in adults. JAMA. 2014;311(5):507.

143. Tsai J, Chien AL. Increased susceptibility to sunburn with hydrochlorothiazide is influenced by race/ethnicity, sex, and treatment duration: Results from the National Health and Nutrition Examination Survey, 2009-2018. J Am Acad Dermatol. https://doi.org/ 10.1016/j.jaad.2021.04.044 (Epub 21 Apr 2021).

144. Mahler HI, Kulik JA, Gerrard M, Gibbons FX. Long-term effects of appearance-based interventions on sun protection behaviors. Health Psychol. 2007;26(3):350-60.

145. Tuong W, Armstrong AW. Effect of appearance-based education compared with health-based education on sunscreen use and knowledge: a randomized controlled trial. J Am Acad Dermatol. 2014;70(4):665-9.

146. Pourciau CY, Eide MJ, Mahan M, Lim HW. Photoprotection counseling of non-white ethno-racial groups: a survey of the practice of expert dermatologists. Photodermatol Photoimmunol Photomed. 2012;28(6):335-7.

147. Kumar P, Kim N. Age-based gaps between awareness of photoaging and photoprotective practices among African American adults. Photodermatol Photoimmunol Photomed. 2021;37(5):428-30.

148. Vespa J, Armstrong DM, Medina L. Demographic turning points for the united states: population projections for 2020 to 2060 . Current population reports. 2020. https://www.census.gov/libra ry/publications/2020/demo/p25-1144.html. Cited 3 Oct 2021. 